\title{
Evolved individual differences: Advancing a condition-dependent model of personality
}

\author{
David M.G. Lewis* \\ Bilkent University, Turkey
}

\section{A R T I C L E I N F O}

Article history:

Received 16 July 2014

Received in revised form 22 September 2014

Accepted 1 October 2014

Available online 20 November 2014

\section{Keywords:}

Personality

Individual differences

Evolutionary psychology

Evolved individual differences

Evolutionary personality psychology

\begin{abstract}
A B S T R A C T
The field of personality psychology offers a wealth of robust empirical research and a successful descriptive taxonomy, but neither explains the origins of the structure of human personality nor elaborates a generative framework for predicting the specific conditions that evoke the development of distinct personality traits. Exploration of traditional personality constructs within an evolutionary adaptive individual differences framework may help fill this explanatory gap. Personality traits exhibit functional features and patterns of variation expected from psychological adaptations designed to solve survival- and reproduction-related challenges recurrently faced during our species' evolutionary history. Conditiondependent evolutionary models of personality have been proposed for decades, but only recently have begun to see empirical investigation. These models posit that species-typical psychological mechanisms take as input cues from the individual's phenotype that would have been ancestrally linked to differential cost-benefit tradeoffs of alternative personality strategies, and produce as output personality trait levels with the greatest probabilistic net benefit for the individual. This paper elaborates a more nuanced conceptual framework that builds on earlier conceptualizations of condition-dependent traits to yield new and untested hypotheses about personality trait variation and covariation. It then describes clear future research directions for empirically investigating these readily testable hypotheses.
\end{abstract}

(c) 2014 Elsevier Ltd. All rights reserved.

\section{Introduction}

At present, the field of personality psychology offers a wealth of robust empirical research and a successful descriptive taxonomy, but does not answer why personality differences take on the structure that they do, or elaborate a generative framework for predicting the specific conditions that evoke the development of distinct personality trait levels. An adaptationist evolutionary psychological approach, which proposes that many human behaviors, cognitions, and emotions are the output of psychological mechanisms designed to solve distinct adaptive problems (Buss, 1995), may offer a cogent predictive framework for identifying the causal processes responsible for the development of personality traits and the social contexts that activate them.

Within an adaptive individual differences framework, different personality traits can be conceptualized as functional strategies that help solve specific problems recurrently faced by members of a species during its evolution (Buss, 2009). In the study of humans, this adaptationist perspective is generally applied using

\footnotetext{
* Address: Bilkent University, Psychology Department, 06800 Bilkent, Ankara, Turkey. Tel.: +1 206525 4479; fax: +1 2065233068 .

E-mail address: david.lewis@bilkent.edu.tr
}

a "top-down" approach (Buss, 1995). First, the researcher identifies a specific challenge to survival or reproduction in ancestral environments. Second, the researcher articulates the behaviors that would have helped solve this adaptive problem, as well as the cognitive processes and emotions that would have motivated these behaviors. The researcher then conducts empirical tests for evidence of these hypothesized, functionally specialized cognitive, affective, and behavioral design features.

Personality psychology has historically operated outside of such an a priori predictive theoretical framework, focusing more on the statistical structure of individual differences than on the potential evolutionary functional origins of those differences (Buss, 1987, 1990, 1991a,b, 1996a,b, 1999; Buss, Larsen, Westen, \& Semmelroth, 1992).

Recent work (e.g., Kanazawa, 2011; Penke, Denissen, \& Miller, 2007; Verweij et al., 2012) has explored multiple potential evolutionary models for individual differences in personality. However, theorists have largely overlooked the possibility that species-typical psychological adaptations produce individual differences in personality, instead favoring models that assume more direct gene $\rightarrow$ personality effects. Given the relative neglect of the powerful, but under-utilized tool of condition-dependent adaptations, this paper places a particular focus on adaptive individual 
differences that emerge from condition-linked differences in the costs and benefits of alternative personality traits.

\subsection{The benefits and costs of personality traits}

Although personality and evolutionary psychology have traditionally had different foci of empirical inquiry, an exploration of the evolutionary functionality of the Five-Factor Model (FFM, Costa \& McCrae, 1985), one of the most widely validated models of human personality and whose dimensions are exhibited in a diverse array of non-human animal species (see Gosling \& John, 1999; Nettle, 2006; Smith \& Blumstein, 2008), illustrates how an adaptationist conceptual framework may be fruitfully applied to the study of human individual differences. The high pole of extraversion in humans, for example, may be conceptualized as an interpersonal strategy that can increase mating opportunities (MacDonald, 2006). High levels of extraversion could lead to increased mating opportunities both directly by engaging potential mates and indirectly by leading to the formation of friendships and social alliances that facilitate increases in status and ascension in the social hierarchy (Denissen \& Penke, 2008; Nettle, 2005, 2006). Data from non-human animals offer evidence consistent with this hypothesized function of extraversion; bold behavior by Trinidadian guppies (Godin \& Dugatkin, 1996), zebra finches (Schuett \& Dall, 2009), and collared flycatchers (Garamszegi, Eens, \& Török, 2008) is associated with increased mating success. A hypothesized function of high agreeableness is that it facilitates successful collective action by leading individuals to deeply engage in and focus on cooperation to achieve group goals (Denissen \& Penke, 2008), an interpersonal orientation that is also invaluable in a long-term mate. Indeed, in some nonhuman species, signals of non-aggressive strategies appear to increase individuals' desirability as long-term mates (see Ophir \& Galef, 2003; Ophir, Persaud, \& Galef, 2005). High levels of conscientiousness are hypothesized to promote successful pursuit of long-term goals such as good health and longevity by means of determination, self-discipline, and delayed gratification (Denissen \& Penke, 2008; Nettle, 2006), and the creative problem-solving capacities exhibited by individuals high in openness to experience may lead to enhanced status and increased mating opportunities (Haselton \& Miller, 2006; Lewis, Al-Shawaf, \& Yilmaz, 2014).

Even high levels of neuroticism, a personality trait that has historically been framed exclusively as "maladaptive" (Grant, 2011, p. 42), may at least partly reflect the output of evolved psychological mechanisms. Several theorists have proposed that humans possess evolved psychological mechanisms designed to elevate neuroticism levels as a functional response to the threat of social exclusion (Denissen \& Penke, 2008; Nettle, 2005, 2006). Higher levels of neuroticism are associated with endogenously driven attentional shifts (Flehmig, Steinborn, Langner, \& Westhoff, 2007), which may guide attention toward negative social outcomes such as relationship exclusion or dissolution. Such selective attention to potential threat cues (Gallagher, 1990; Hemenover \& Dienstbier, 1996) and focusing on negative information (Hemenover, 2001) may result in greater sensitivity to potential negative social outcomes (Grant, 2011; Kuppens \& Van Mechelen, 2007), as well as greater worry and anxiety in response to potential relationship threats. In turn, these cognitive and affective states may motivate behaviors such as vigilance and guarding of one's relationship partners to protect limited relationship opportunities (Denissen \& Penke, 2008; Nettle, 2005, 2006).

The key idea is that traditional personality constructs are not only amenable to exploration within an adaptive individual differences framework, but also exhibit characteristics expected of psychological adaptations designed to solve fitness-relevant problems recurrent in human ancestral environments.
Although a given strategy on a particular personality dimension may serve reproductive benefit-linked functions, each strategy also carries potential costs. In non-human species, exploratory or bold behavior may increases risk of predation (guppies: Dugatkin, 1992; Godin \& Davis, 1995; theoretical model: Wolf, van Doorn, Leimar, \& Weissing, 2007; for review, see Smith \& Blumstein, 2008), and among humans, extraversion can similarly carry fitness-relevant costs - extraverts are disproportionately represented in hospitals with injury or illness (Nettle, 2005) and their pronounced sensation-seeking can lead to traumatic injury (Field \& O'Keefe, 2004) and legal trouble (Ellis, 1987). Similarly, high levels of agreeableness can carry fitness costs; individuals who avoid conflict are less desirable as mates in a variety of species, including humans (e.g., fighting fish: Doutrelant \& McGregor, 2000; Midas cichlid: Barlow, 1986; humans: Lukaszewski \& Roney, 2011), and high agreeableness may lead individuals to forgo their own objectives and risk social exploitation (Judge, Livingston, \& Hurst, 2011). Although high levels of neuroticism may cognitively and affectively motivate an individual to protect limited social opportunities, high neuroticism is associated with impaired somatic health (Cohen \& Williamson, 1991; Glaser \& Kiecolt-Glaser, 2005; Herbert \& Cohen, 1993; O'Leary, 1990) and can place burdensome strain on social relationships (e.g., Buss, 1991a; Neeleman, Sytema, \& Wadsworth, 2002). Even high conscientiousness, a trait rarely regarded as undesirable, may lead individuals to forgo unanticipated, but valuable opportunities. Importantly, this includes opportunities that could dramatically increase reproductive fitness, such as opportunistic short-term mating (Schmitt, 2004). Although high openness is associated with greater creativity, it is also associated with social withdrawal, delusional thoughts, and risk for schizophrenia and related disorders (McCreery \& Claridge, 2002; Nettle, 2009). In short, the pursuit of any given personality strategy is associated with both potential benefits and potential costs (Buss, 1990; DeKay \& Buss, 1992).

\subsection{Cost-benefit tradeoffs: individual differences}

The benefits of pursuing a given personality strategy depend on whether an individual faces the adaptive challenge the personality strategy is designed to help solve, how effective the strategy is in solving the adaptive problem for that particular individual, and the benefits that accrue to the individual by successfully solving the problem (Buss, 2009; Denissen \& Penke, 2008; Nettle, 2006; Penke et al., 2007). The costs of the strategy depend on the potential costs inherent to the strategy itself (e.g., extraversion-associated injury risk) and the likelihood of the individual incurring those costs, as well as the opportunity costs to the individual the benefits that the individual would obtain by pursuing an alternative strategy.

Crucially, these variables influencing the cost-benefit tradeoffs of a given personality strategy differ across individuals as a function of their condition. An organism's condition refers to its phenotypic quality (e.g., physical attractiveness, strength, see Lukaszewski \& Roney, 2011), and reflects the organism's “ability to efficiently convert energy into fitness-enhancing traits and outcomes" (Lukaszewski, Larson, Gildersleeve, Roney, \& Haselton, 2014), or "overall fitness budget" (Gangestad, Merriman, \& Thompson, 2010; Tomkins, Radwan, Kotiaho, \& Tregenza, 2004).

A condition-dependent evolutionary psychological model posits that species-typical psychological mechanisms take as input condition-linked cues predictive of differential costs and benefits of alternative personality strategies in ancestral conditions, and produce as output the personality strategy of greater probabilistic net benefit for the individual, given his or her condition (see Tooby \& Cosmides, 1990 for their seminal theoretical discussion of this 
issue; see also Buss \& Greiling, 1999; Nettle, 2006; Wolf et al., 2007).

Considering the condition-dependent costs and benefits of extraversion helps to illustrate this concept. Extraversion draws attention to one's characteristics (Anderson \& Shirako, 2008; Ashton \& Lee, 2007; Nettle, 2005), which can advertise one's positive attributes, but also initiate competition and provoke conflict with rivals (Lund, Tamnes, Mouestue, Buss, \& Vollrath, 2007). The benefits of broadcasting information about one's physical characteristics are not uniform across individuals - it is more beneficial for attractive than unattractive individuals. Similarly, engaging in potentially conflict-initiating social behaviors is more costly for less physically formidable individuals (McDonald, Navarrete, \& Van Vugt, 2011). Consequently, the net benefits of extraversion are likely higher for stronger and more attractive individuals (Benson, Karabenick, \& Lerner, 1976). If the psychological mechanisms responsible for the introversion-extraversion continuum calibrate the manifest behavior they produce according to cues linked to these costs and benefits, then we should expect stronger and more attractive individuals to exhibit higher levels of extraversion. Indeed, individual differences in attractiveness and strength are predictive of individual differences in extraversion (Lukaszewski \& Roney, 2011).

Relationships between individuals' psychological and morphological attributes have been documented since early in the history of personality psychology (e.g., Kretschmer, 1931; Sheldon, 1940, 1942). However, without an articulation of the process by which individuals' morphological condition and personality are connected, these condition-personality links lack a cogent explanation - let alone a powerful theoretical tool for predicting which facets of an individual's condition should be linked to which personality dimensions and in which direction.

At first blush, the postulation that humans possess speciestypical psychological adaptations that calibrate personality levels according to an individual's condition might not immediately appear to accord with the known stability of individual differences in personality (Caruso, 2000). However, considering the patterns that condition-dependent personality mechanisms would be expected to produce reveals how a condition-dependent model of personality actually predicts stable individual differences. To illustrate this point, let us further explore the hypothesis that species-typical psychological mechanisms calibrate individuals' neuroticism levels according to the individual's threat of social exclusion, which varies at least partly as a function of the individual's condition (Denissen \& Penke, 2008; Nettle, 2005, 2006).

\subsection{Personality stability}

Neuroticism's stability may be at least partially accounted for by temporally and cross-situationally stable links between individuals' morphology-based desirability as a relationship partner and their social exclusion. Throughout the lifespan and across social domains, individuals who possess a less desirable morphological phenotype experience less social acceptance - and exhibit higher levels of neuroticism (Mathes \& Kahn, 1975). Less attractive newborns are viewed as less intelligent, likeable, and good (Stephan \& Langlois, 1984), and a less attractive child's transgressions are both treated as more severe and more likely to be attributed to dispositional issues (Dion, 1972). In preschool, less attractive children are conferred lower social status (Vaughn \& Langlois, 1983), and less attractive and athletic individuals experience more rejection by their peers in childhood and adolescence (Vannatta, Gartstein, Zeller, \& Noll, 2009). In adulthood, less attractive individuals are discriminated against as potential mates and experience a more adverse mating environment (e.g., Buss, 1989; Buss \& Barnes, 1986; Waynforth, 2001). This lifelong exclusion of individuals with less desirable morphological profiles may at least partly account for the cross-situational and temporal stability of neuroticism. If (i) humans possess psychological mechanisms that calibrate individuals' neuroticism levels according to cues linked to their likelihood of being social excluded (Denissen \& Penke, 2008), (ii) individuals' likelihood of being socially excluded is stably linked to their desirability as a social partner, and (iii) their desirability as a relationship partner depends - even if only partly - on their profile of morphological attributes, then we should expect those individuals with less desirable morphological profiles to exhibit higher neuroticism across time and context. In short, we should expect species-typical, condition-dependent psychological adaptations to produce stable individual differences in personality (see also Buss \& Greiling, 1999 for their discussion of "enduring situational evocation").

Moreover, if this postulation that condition-dependent mechanisms produce stable personality differences as a consequence of taking as input condition-linked cues that inherently exhibit high levels of stability (e.g., physical attractiveness, formidability), then individuals might be able to infer others' personality trait levels at above chance levels even at zero acquaintance (e.g., merely by looking at photograph of the individual). Indeed, there are multiple extant studies in support of this speculation. Shackelford and Larsen (1997) photographed participants, took measurements of participants' facial symmetry from these photographs, and used these symmetry assessments to predict participants' personality levels. They found a positive association between individuals' facial symmetry and extraversion, a finding that has subsequently been replicated by Fink, Neave, Manning, and Grammer (2005) and Pound, Penton-Voak, and Brown (2007), the latter of whom provided convergent evidence for this finding by employing a distinct method. More recently, Holtzman, Augustine, and Senne (2011) expanded on this research by examining the relationship between individuals' facial symmetry (as assessed from static photographs) and a broader range of personality dimensions. They found significant associations between facial symmetry and 44 dimensions of individual differences, ranging from the Big 5 factors to individual facet levels, and from socially aversive to pro-social traits. Collectively, this group of findings suggests that individuals' personality level may be able to be inferred, with some degree of accuracy, merely from photographs of the individuals. More broadly, these findings are unambiguously consistent with the overarching proposal that condition-dependent psychological mechanisms can produce stable individual differences in personality as a consequence of calibrating their output according to stable, conditionlinked variables.

\subsection{The heritability of personality}

The proposal of species-typical personality mechanisms is also ostensibly inconsistent with the heritability of personality traits (Penke et al., 2007). The heritability observed in personality traits would not necessarily be the pattern expected of species-typical adaptations; selection often leads to zero heritability as a consequence of favoring the genetic variant with the greatest replicative fitness to the point of the extinction of alternative genetic variants. Stated differently, directional selection in favor of the highestfitness genetic variant reduces variation at that genetic locus until that allele becomes a virtually universal feature of a species' genome. By definition, then, species-typical adaptations should exhibit virtually zero heritability at the genetic loci involved in the building of that adaptation.

A number of evolutionary biologists and geneticists have interpreted the heritability of manifest personality as evidence for variation in the genes involved in the construction of the psychological 
mechanisms responsible for producing personality (Nettle, 2006; Penke et al., 2007).

There are several known polymorphisms associated with individual differences in personality. For example, neuroticism is associated with the short allele of the DRD4 exon III polymorphism (Tochigi et al., 2006); the number of CAG repeats at the androgen receptor (AR) gene in men (Westberg et al., 2009); the serotonin transporter promoter 5-HTTLPR short allele (Sen, Burmeister, \& Ghosh, 2004); and the GABA(A) Alpha 6 receptor Pro385Ser Pro allele (Sen et al., 2004). Extraversion is also associated with the number of CAG repeats at the AR locus (Lukaszewski \& Roney, 2011; Westberg et al., 2009).

However, (1) models of personality based on genetic polymorphisms leave the lion's share of inter-individual variation in personality unexplained (e.g., see Westberg et al., 2009), and (2) it is unclear whether these genetic polymorphisms are associated with differences in the psychological mechanisms responsible for personality, or with individual differences in the characteristics that serve as input cues into personality mechanisms and thereby influence their output.

If the psychological mechanisms that produce personality are designed to take as input cues associated with differential costs and benefits of alternative strategies, and at least a subset of these cues includes heritable, non-personality attributes such as physical attractiveness and strength (Lukaszewski \& Roney, 2011), then we should expect personality to show heritability in behavioral genetics studies - as the output of species-typical, condition-dependent mechanisms.

Lukaszewski and Roney's (2011) discovery of a link between the AR gene and extraversion illustrates this point clearly. If (i) individuals' physical attractiveness and strength vary as a function of alternative genetic variants at the AR gene, (ii) the costs and benefits of extraversion vary as a function of individuals' physical attractiveness and strength, and (iii) the humans possess psychological mechanisms that calibrate manifest extraversion levels as a function of cues linked to differential costs and benefits of alternative strategies on the introversion-extraversion continuum, then we would expect - on a priori grounds - extraversion to exhibit heritability - even as the output of universal psychological mechanisms (see Tooby \& Cosmides, 1990, for their seminal discussion of this concept of indirect, or "reactive," heritability).

Recent research asserts that a mutation-selection balance model - but not a condition-dependent model - can account for heritable variation in personality (Verweij et al., 2012). This research, however, betrays the misconception that these two models predict different patterns of heritable variation. Verweij et al. (2012) compare observed patterns of heritable variation to those expected under three models: balancing selection, selective neutrality, and mutation-selection balance. Under a balancing selection model, genetic variation underling personality differences is maintained by changing selection pressures across environments. For example, an allele that predisposes individuals to higher levels of neuroticism could be favored in environments in which relationship stability and fidelity are low, but would be outperformed by an allele associated with lower levels of neuroticism in environments in which relationship stability and fidelity are high. However, a condition-dependent mechanism that calibrated individuals' neuroticism levels according to their desirability as a relationship partner, local levels of relationship stability and fidelity, or other inputs linked to differential costs and benefits of neuroticism would have been favored by selection over a mechanism insensitive to these cues. Given the known capacity of selection to craft such condition-dependent mechanisms, it is not highly plausible that heritable variation in personality can be predominantly explained by balancing selection.

A selective neutrality model, on the other hand, attempts to account for heritable variation in personality by proposing that genetic variants underlying personality differences are unaffected by selection because they are unrelated to fitness outcomes. However, given that personality differences are linked to fitness-relevant variables such as attractiveness (Lukaszewski \& Roney, 2011), mating behavior (Zietsch, Verweij, Bailey, Wright, \& Martin, 2010), and number of offspring produced (Jokela, Kivimaki, Elovainio, \& Keltikangas-Jarvinen, 2009), selective neutrality is a rather implausible explanation for genetic variation in personality. It is perhaps unsurprising, then, that Verweij et al. (2012) conclude that neither selective neutrality nor balancing selection can account for observed patterns of heritable variation in personality. However, they erroneously categorize a condition-dependent model as being subsumed under selective neutrality, and conclude that extant data are consistent with mutation-selection balance.

This mischaracterization of a condition-dependent model leads to a critical oversight: the failure to realize that the patterns of genetic variation expected under a mutation-selection balance model and a condition-dependent model are identical. A mutation-selection balance model acknowledges that directional selection favors, among existing genetic variants, the allele associated with the most optimal trait levels, and eliminates alternative alleles. Although selection is constantly reducing genetic variation by purging these lower fitness alleles, this is an iterative process across generations that is inexorably accompanied by an influx of mutations that introduce new genetic variation. Verweij et al. (2012) are not unjustified in their conclusion that the observed heritable variation associated with personality is most consistent with mutation-selection balance. However, they jump to the unwarranted conclusion that the genetic loci under mutationselection balance are specifically those that code for the mechanisms that produce personality.

An equally plausible alternative is that the loci under mutationselection balance are those that code for the traits that serve as inputs to personality-producing mechanisms. Both of these perspectives represent mutation-selection balance models, so are thus equally consistent with extant data. However, the latter view is a condition-dependent model - a condition-dependent model is a mutation-selection balance model.

To illustrate this important point, let us consider polymorphism at the AR locus. Different alleles at the AR locus are associated with individual differences in attractiveness and strength, as well as individual differences in extraversion. If the AR gene is directly involved in the building of psychological mechanisms that calibrate extraversion levels, then we would not necessarily expect morphological correlates downstream from the gene, such as attractiveness and strength, to exhibit links to extraversion independent of the gene itself. Alternatively, if humans possess psychological adaptations designed to calibrate extraversion levels according to condition-based cues like attractiveness and strength, then we would expect links between these input cues and the output of these mechanisms. Strongly consistent with this conditiondependent model, individual differences in attractiveness and strength predict extraversion levels - above and beyond genetic polymorphism (Lukaszewski \& Roney, 2011). This relationship between genetics, physical attractiveness, strength, and extraversion offers a clear empirical example of how species-typical, condition-dependent psychological mechanisms can produce heritable personality outcomes.

In sum, a condition-dependent model of personality proposes that if psychological mechanisms calibrate manifest personality trait levels according to condition-linked inputs such as physical attractiveness and strength, and these attributes exhibit heritability in behavioral genetic studies, then patterns of heritable variation in personality may actually reflect heritable variation in these inputs, rather than in the psychological mechanisms sensitive to those inputs. 
There are two crucial points for personality researchers to note. First, there is no strong reason to believe that a single model must account for all heritable variation in personality. Human personality exhibits heritable variance on manifold dimensions. There may be different evolutionary origins for variance on each of these dimensions, and within each dimension, different models may account for distinct proportions of variance. Evidence suggesting an important role of mutation-selection balance in the evolution of human personality is not tantamount to evidence of an absence of other selective and non-selective forces at work.

Second, because a mutation-selection balance model and a condition-dependent model predict identical patterns of heritable variation, no pattern of heritable variation in personality could adjudicate between a mutation-selection balance model and a condition-dependent model. Instead, demonstrating functional design of the psychological mechanisms that produce personality differences ultimately will be necessary to discriminate between these alternatives. Testing for this discriminative evidence represents a key future research direction for an evolutionary approach to personality, as discussed in greater detail below.

\section{The future of evolutionary personality psychology}

\subsection{Experimental studies}

The correlational nature of research that has tested evolved condition-dependent models of personality (e.g., Lukaszewski, 2013) renders such research unable to establish the causal direction of observed condition-personality links. Establishing whether there is a causal direction from condition-linked input to manifest personality output is necessary for adjudicating between the mutation-selection and condition-dependent alternatives. To more directly test the hypothesis that humans possess psychological adaptations designed to calibrate personality trait levels according to cues linked to the adaptive problems that distinct personality strategies were designed to solve, a combination of experimental and longitudinal designs is needed.

Here, I outline a general experimental framework by which a condition-dependent model could be tested. The overall hypothesis of species-typical, evolved condition-dependent mechanisms is that they should output different personality trait levels as a function of individual differences in cues ancestrally linked to the probability of facing the adaptive challenges that alternative personality strategies were designed to solve. In natural settings, condition-linked differences in the frequency and/or strength at which a relevant adaptive problem is faced should result in the hypothesized personality mechanisms producing individual differences in trait levels. Correlational studies (e.g., Lukaszewski, 2013) have shown precisely this pattern.

However, in contexts or environments that present unambiguous cues indicating that the relevant adaptive challenge is not being faced, the mechanisms responsible for producing the personality strategy that evolved to help solve that challenge should be deactivated, regardless of the individual's condition. In response to unambiguous cues that the relevant adaptive challenge is being faced, such unequivocal evidence should activate the personality strategy in all individuals, irrespective of their condition. On the other hand, under conditions of uncertainty - like those that characterize the vast majority of natural settings - manifest personality trait levels should track individuals' condition (e.g., on dimensions such as physical attractiveness and formidability, Lukaszewski \& Roney, 2011) because these condition-linked cues would have been statistically associated with facing the relevant adaptive challenge in ancestral conditions.

An unpublished dissertation by Lewis (2013) testing the hypothesis that evolved psychological mechanisms calibrate individuals' neuroticism levels as a condition-dependent response to social exclusion (Denissen \& Penke, 2008; Nettle, 2005, 2006) provides evidence consistent with this series of hypotheses. Exactly as would be expected if humans universally possess evolved, neuroticism-calibrating adaptations that "lie dormant until they are activated by cues signaling that [the] adaptive problem is being confronted" (Buss \& Shackelford, 1997), Lewis found that individuals' exhibited lower levels of manifest neuroticism when their inclusion in social relationships was certain, regardless of their condition. Comparatively, individuals exhibited increased manifest neuroticism in response to situations indicating certain exclusion, irrespective of their condition. However, under conditions in which social cues were insufficient for participants to ascertain their social status with absolute certainty - a constraint that would have characterized the vast majority of ancestral conditions - individuals' neuroticism levels adaptively varied as a function of their condition.

Collectively, these findings and the evolutionary model motivating their discovery concurrently highlight (1) the "power of the situation" to create "potent forces producing or constraining behavior" (quoting Ross \& Nisbett, 1991, p. 9, but see Tooby \& Cosmides, 1990), and (2) the importance of individual differences and the person (Funder \& Colvin, 1991; Ozer, 1985; Roberts, Kuncel, Shiner, Caspi, \& Goldberg, 2007). This nuanced nature of human psychology, which resonates with and brings together core assertions from social and personality psychology, highlights the heuristic value and unifying potential of an fully interactionist evolutionary theoretical framework.

\subsection{Evolved psychological mechanisms and the input power of the situation and person}

The situation-mediated links between condition and personality described by Lewis (2013) highlight the predictive power of an evolutionary theoretical framework across the false boundaries that have historically separated personality and social psychology. This highlights not only that an evolutionary perspective can offer a unifying meta-theoretical framework for these sub-disciplines, but also that they must be integrated to achieve a mature understanding of human psychology.

These condition-situation-personality links may also inform an understanding of the information-processing structure of evolved psychological mechanisms. For an exemplary illustration of the information-processing structure of an evolved psychological mechanism, let us examine Lieberman, Tooby, and Cosmides' "kinship estimator" (2003, 2007).

Lieberman and colleagues postulate that psychological adaptations to identify and direct altruism toward kin are designed to take as input cues recurrently linked to genetic relatedness in ancestral environments (Lieberman, Tooby, \& Cosmides, 2003, 2007). This kinship-estimating mechanism takes multiple cues (e.g., observing a newborn nursing from one's own mother, Lieberman et al., 2003, 2007; facial resemblance, Lewis, 2011) as input; hierarchically treats them according to (a) their ancestral predictive validity (i.e., their correlations with actual genetic relatedness) and (b) the presence or absence of more valid cues; and calibrates the outputs of kin-directed altruism and anti-incestuous sentiment according to this interaction of cues (Lewis, 2011; Lieberman et al., 2003, 2007).

Generalizing these conjectures, selection would have favored mechanisms that were designed to (i) take multiple cues as input, (ii) hierarchically treat those cues, prioritizing those that would have greater predictive validity, and (iii) produce emotional and behavioral solutions to the adaptive problem indicated by available cues. 
Lewis (2013) provides further empirical support for this model of the information-processing structure of evolved psychological mechanisms, including personality-calibrating mechanisms. Unequivocal indicators of an adaptive problem inherently would have been the most valid cues that that adaptive problem was being faced. An individual's condition, even if recurrently statistically linked to facing a particular adaptive problem, would have been a less valid cue (e.g., see Kurzban \& Leary, 2001). Given the greater predictive validity of unequivocal social cues, the postulated personality-calibrating mechanisms would be expected to adjust their output according to such cues when they were available, but to calibrate their output according to the cues linked to the individual's condition when such unequivocal cues were unavailable. As expected, Lewis (2013) found that when unambiguous indicators of the relevant adaptive problem were present, individuals' manifest personality trait levels were calibrated according to these cues (and less valid, condition-based cues had no effect). However, when such unequivocal cues were absent, individual's personality trait levels were calibrated according to condition-based cues.

These findings direct focus on the information-processing structure of these mechanisms - an important facet of human psychology that, to date, has been relatively neglected by research informed by an evolutionary psychological framework. In its young history, evolutionary psychology has produced a robust body of novel findings about ancestral adaptive problems and the psychological output (e.g., emotions, behaviors) that could have helped solve these problems. However, substantially less direct attention has been given to the information-processing architecture of these mechanisms responsible for these manifest psychological phenomena. This gap is not trivial; the psychological and behavioral output of these mechanisms - our psychology - depends not on the cues to the adaptive problem per se, but rather on the evolved algorithms with which the mechanisms process these cues. For evolutionary psychological research to be most consistent with its conceptual foundations, greater explicit attention should be directed toward the information-processing algorithms of humans' psychological adaptations. Focusing on the design features of psychological adaptations at all three levels of information-processing - input cues, information-processing algorithm, and manifest psychological output -will be key to gleaning the full range of insight that an evolutionary psychological approach can offer to personality psychology, and to psychology as a whole.

To offer a more complete investigation into humans' psychological adaptations - including the postulated mechanisms responsible for calibrating personality levels - future research should be characterized by a balanced emphasis on these three distinct, but interrelated foci. First, research should identify the specific cues (e.g., social, phenotypic) that would have been recurrently linked to facing a particular adaptive problem (and thus the cost-benefit tradeoffs of alternative personality strategies), as these cues represent likely candidates to serve as inputs into evolved personalitycalibrating mechanisms (Buss, 1991b; Tooby \& Cosmides, 1990). Second, it is key that future research explicitly articulates the hypothesized information-processing structure of the posited mechanisms, including the mechanisms' computational ("decision-making") procedures. Understanding the mechanisms' information-processing design features will be indispensable to explaining and predicting the mechanisms' output - human personality.

\subsection{Common calibration and personality trait covariation}

By these systematic means, a condition-dependent model of personality may be able to offer new theoretical and empirical insight into personality variation and personality covariation. If (a) humans possess evolved psychological mechanisms that calibrate personality levels according to condition-linked cues ancestrally associated with differential cost-benefit tradeoffs of alternative personality strategies, and (b) the cost-benefit tradeoffs of multiple personality traits were linked to an individual's condition, then individual differences in condition should lead to individual differences on multiple personality dimensions simultaneously (Lukaszewski, 2013; Tooby \& Cosmides, 1990).

Indeed, recent research has shown that trait covariation is substantially reduced after controlling for cues hypothesized to have radiating influences on multiple personality dimensions (Lukaszewski, 2013). This at least tentatively suggests that different dimensions of personality covary as a consequence of "common calibration" based on these shared input cues (Buss, 2009; Dall, Houston, \& McNamara, 2004; Tooby \& Cosmides, 1990).

A key issue remaining to be addressed is whether these trait intercorrelations reflect the output of a single mechanism that simultaneously calibrates multiple dimensions of personality traits (for a sophisticated evolutionary discussion of trait covariation traceable to life history strategy, see Figueredo et al., 2005; see also Digman, 1997; McCrae \& Costa, 2008; Rushton \& Irwing, 2008; Funder, 2001), or are due to the calibration of multiple distinct personality mechanisms by shared input cues. To empirically adjudicate between these competing hypotheses, future research should test their divergent predictions. To identify the predictions that the multiple mechanism perspective yields, it is helpful to consider why these mechanisms would be expected to take as input the particular cues that they do: because those cues would have been recurrently linked to specific adaptive problems in ancestral environments. Under the multiple mechanism view, we might expect multiple mechanisms to have shared input cues because those cues were recurrently linked to the distinct adaptive problems that each of the mechanisms was designed to solve. For example, if neuroticism and extraversion evolved to help individuals deal with the threat of relationship exclusion and secure mating opportunities, respectively, and individuals' mate value was linked to both of these adaptive problems, then we would expect mate value to exert common calibrational effects on both of these personality dimensions. However, for those cues that (a) were recurrently linked to an adaptive problem that one personality strategy (e.g., high Openness) evolved to solve, but (b) were unlinked to the adaptive problem a different strategy (e.g., high Agreeableness) evolved to solve, we should expect calibration of the former trait, but not of the latter. That is, cues to an adaptive problem that one personality strategy was designed to solve but whose solution was ancestrally unrelated to individual differences on another personality dimension, should result in calibration of the former personality trait, but not the output of mechanisms responsible for calibrating individual differences on personality dimensions.

Future research should thus (1) articulate the adaptive problems each personality strategy is hypothesized to be designed to solve; (2) identify phenotypic, social, or other cues that should have been recurrently linked to those adaptive problems; and (3) distinguish between those cues that would have been linked to multiple adaptive problems and those that would have been discriminatively indicative of an adaptive problem whose successful solution would have been associated with a particular strategy on one, but not other, personality dimensions. Research should then design studies to examine whether exposure to cues linked to multiple adaptive problems is associated with trait intercorrelations, whereas exposure to cues indicative of a specific adaptive problem is associated with individual differences in the relevant personality dimension but not others. Such future research should help discriminate between the single trait factor and multiple mechanism hypotheses and further advance our understanding 
of the psychological mechanisms responsible for individual differences in personality.

\subsection{Longitudinal studies: changes in cost-benefit tradeoffs during the lifespan}

Relative to correlational studies, experimental studies can more discriminatively test a condition-dependent model by virtue of demonstrating a causal relationship between input cues and manifest personality output. However, single-session experimental studies are inherently limited in that they can only test for "snapshot" shifts in personality levels. Cross-sectional, experimentbased data are thus unable to speak directly to whether personality mechanisms calibrate individuals' "trait" levels across the lifespan in response to changes in condition (e.g., physical attractiveness, formidability), social circumstances, or other phenotypic or environmental conditions (see Buss \& Penke, 2014). Experimentally induced changes in adults' manifest personality levels (see Lewis, 2013) are consistent with the proposal that personality-producing mechanisms can recalibrate their output, but cannot conclusively demonstrate that changes in the costs and benefits of alternative personality strategies across the lifespan are associated with "trait"-level shifts. Given the known temporal stability of personality traits, longitudinal research assessing changes in personality over time will be necessary for testing the heuristic value of a condition-dependent model for personality psychology.

Longitudinal designs are also an important research direction for answering another interesting theoretical but empirically unexplored issue: when during development or the lifespan the mechanisms responsible for producing personality calibrate their output (Duckworth, 2010). The timing of personality calibration during the lifespan may itself reflect a design feature of the mechanisms that produce personality. On one hand, ancestrally, adolescence could have been a critical period for the "crystallization" of personality strategies, since performance at that life stage would have been a strong predictor of future performance. On the other hand, individuals may experience significant changes in condition across the lifespan due to, for example, the development or deterioration of formidable physical characteristics; the formation or dissolution of valuable social alliances; or disease, illness, or injury. Because these changes would have been associated with shifts in the cost-benefit tradeoffs of alternative personality strategies, there would have been costs associated with "crystallizing" a personality strategy too firmly. For example, an extraverted personality strategy may be associated with many benefits and relatively few costs for men who are high in physical attractiveness and formidability (Lukaszewski \& Roney, 2011). Ceteris paribus, these men would have been both desirable to women as mates (e.g., Buss, 1989; Buss \& Schmitt, 1993; Li, Bailey, Kenrick, \& Linsenmeier, 2002; Li \& Kenrick, 2006), and able to successfully vie for status against intrasexual competitors, including when this competition involved physical conflict. However, if such a high mate value man were to suffer from an injury or illness that decreased his physical formidability or attractiveness, the probabilistic costs of an extraverted strategy would increase, and the benefits would decrease. Conversely, if some men experienced increases in mate value later in life, such as via the death of higher ranking males within their group or other forms of social hierarchy restructuring that conferred newfound status on these men, then selection would have favored mechanisms that enabled these men to capitalize on their newly elevated status by shifting their extraversion and other personality trait levels (see Buss, 2000, for a discussion of critical events that may recalibrate personality trait levels).

Even in the absence of mate value changes - or in spite of them - shifts in life stages also change the cost-benefit tradeoffs of personality strategies. For example, as older adults move away from direct reproductive effort, the fitness benefits associated with neuroticism's hypothesized anti-infidelity functions decrease (see Lewis, 2013). That is, in spite of older adults' mate value decreasing with age - a change that may be associated with greater threat of one's mate's infidelity during direct reproductive stages of adulthood - the net benefits of neuroticism may decrease as older adults age. Consistent with the proposition that humans' possess personality-calibrating mechanisms that are sensitive to developmental stages that shift the cost-benefit tradeoffs of alternative strategies, women's neuroticism decreases with age (Srivastava, John, Gosling, \& Potter, 2003) - even though their reproductive value decreases (Daly \& Wilson, 1983).

In sum, the countervailing costs and benefits of personality crystallization and personality flexibility (Dall et al., 2004; Sih, Bell, Johnson, \& Ziemba, 2004; Tufto, 2000) may have led to the evolution of mechanisms that crystallize individuals' personality trait levels within a certain range based on input during delimited periods of life (Buss, 2009; Dall et al., 2004; Tooby \& Cosmides, 1990), but also produce adaptive local shifts from these baseline levels as the cost-benefit tradeoffs of alternative personality strategies change across the lifespan.

A key focus of a future research agenda should be longitudinal designs that track within-individual changes in the phenotypic characteristics or social environments hypothesized to serve as input into personality-calibrating mechanisms. Assessing the relationship between these changes and shifts in individuals' levels of personality "traits" will enable more direct testing of the hypothesis that personality mechanisms both crystallize individuals' "traits" to some degree and later calibrate them according to phenotypic, social, or other environmental changes that shift the cost-benefit tradeoffs of different personality strategies.

\section{Conclusions}

This paper outlines the theoretical insight that the evolutionary psychological heuristic of condition-dependent adaptations may offer to the study of personality and individual differences. Extant research (e.g., Lewis, 2013; Lukaszewski, 2013; Lukaszewski \& Roney, 2011; Simmons \& Roney, 2011) offers promising initial empirical demonstrations of the value of this theoretical tool. However, it is the continued and refined application of this framework that will reveal its true value for personality psychology. Three future directions are of particular importance on a research agenda for applying this theoretical tool to the study of individual differences.

First, future research should more explicitly investigate the information-processing design features of the psychological mechanisms responsible for producing personality. First, researchers should identify condition-linked, social, and other environmental cues associated with the likelihood or frequency at which ancestral humans faced fitness-relevant adaptive challenges. This simultaneous identification of both condition-based and social cues will lead to novel, theoretically anchored $a$ priori hypotheses about important social and individual influences - and their interaction - on human psychology. Second, researchers should identify the predictive validities of these cues in indicating the presence of the adaptive challenge, because this may shed valuable insight on the computational architecture of the mechanism's decisionmaking procedures; selection would have favored mechanisms that hierarchically treated distinct social and individual-based cues and prioritized the most strongly predictive cues.

These two steps will guide, in a theoretically anchored manner, a particular focus toward the relatively neglected informationprocessing stage of the mechanism's decision rule, and help offer a more comprehensive perspective on our evolved 
information-processing mechanisms. Importantly, these theoretically principled steps may yield novel, a priori predictions that lead to the discovery of facets of social and personality psychology that otherwise might be left uncovered.

Second, future research should discriminate between two classes of cues: those that would have been ancestrally linked to differential cost-benefit tradeoffs on multiple personality dimensions, and those that would have been uniquely linked to a particular adaptive problem that a specific personality strategy was designed to solve. This distinction will be important, because the evolutionary heuristic of condition-dependent adaptations yields divergent predictions about the patterns of personality variation expected to result from calibration to these different classes of cues. Specifically, the first class of cues would be expected to calibrate multiple personality dimensions simultaneously and result in trait covariation, whereas the second class would be expected to exert calibrational effects on individual dimensions of personality independent of other dimensions.

Third, longitudinal studies should systematically investigate shifts in personality "trait" levels across the lifespan as a function of changes in phenotypic, social, or other cues ancestrally linked to important adaptive problems. These ideas represent important steps toward the development of a deeper and more sophisticated explanatory framework for personality variation and covariation.

At present, the field of personality psychology is characterized by a wealth of robust empirical research and a successful descriptive taxonomy. However, researchers have yet to uncover an answer to the fundamental question of why human personality is structured this way. The particular evolutionary psychological approach outlined here - that of condition-dependent mechanisms - may help move toward a more comprehensive understanding of the origins of personality variation, and thus holds promise as a predictive and explanatory framework for enriching research on human personality. It is my hope that the continued development, refinement, and application of this framework will contribute to the increasing sophistication and progress of personality psychology.

\section{References}

Anderson, C., \& Shirako, A. (2008). Are individuals' reputations related to their history of behavior? Journal of Personality and Social Psychology, 94(2), 320-333. http://dx.doi.org/10.1037/0022-3514.94.2.320.

Ashton, M. C., \& Lee, K. (2007). Empirical, theoretical, and practical advantages of the HEXACO model of personality structure. Personality and Social Psychology Review, 11(2), 150-166. http://dx.doi.org/10.1177/1088868306294907.

Benson, P. L., Karabenick, S. A., \& Lerner, R. M. (1976). Pretty pleases: The effects of physical attractiveness, race, and sex on receiving help. Journal of Experimental Social Psychology, 12(5), 409-415. http://dx.doi.org/10.1016/00221031(76)90073-1.

Barlow, G. W. (1986). Mate choice in the monogamous and polychromatic Midas cichlid, Cichlasoma citrinellum. Journal of Fish Biology, 29, 123-133. http:// dx.doi.org/10.1111/j.1095-8649.1986.tb05004.x.

Buss, D. M. (1987). Selection, evocation, and manipulation. Journal of Personality and Social Psychology, 53(6), 1214-1221.

Buss, D. M. (1990). Toward a biologically informed psychology of personality. Journal of Personality, 58, 1-16.

Buss, D. M. (1989). Sex differences in human mate preferences: Evolutionary hypotheses tested in 37 cultures. Behavioral and Brain Sciences, 12, 1-14. http:/ dx.doi.org/10.1017/S0140525X00023992.

Buss, D. M. (1991a). Conflict in married couples: Personality predictors of anger and upset. Journal of Personality, 59(4), 663-703.

Buss, D. M. (1991b). Evolutionary personality psychology. Annual Review of Psychology, 42, 459-491.

Buss, D., \& Schmitt, D. P. (1993). Sexual strategies theory: An evolutionary perspective on human mating. Psychological Review, 100(2), 204-232.

Buss, D. M. (1995). Evolutionary psychology: A new paradigm for psychological science. Psychological Inquiry, 6, 1-30.

Buss, D. M. (1996a). Paternity uncertainty and the complex repertoire of human mating strategies. American Psychologist, 51(2), 161-162.

Buss, D. M. (1996b). Social adaptation and five major factors of personality. In J. S. Wiggins (Ed.), The five-factor model of personality: Theoretical perspectives (pp. 180-207). New York: Guilford.
Buss, D. M. (1999). Adaptive individual differences revisited. Journal of Personality, 67(2), 259-264.

Buss, D. M. (2000). The dangerous passion: Why jealousy is as necessary as love and sex. New York: The Free Press.

Buss, D. M. (2009). How can evolutionary psychology successfully explain personality and individual differences? Perspectives on Psychological Science, $4(4), 366$

Buss, D. M., \& Barnes, M. (1986). Preferences in human mate selection. Journal of Personality and Social Psychology, 50(3), 559-570. http://dx.doi.org/10.1037/ 0022-3514.50.3.559.

Buss, D. M., Larsen, R. J., Westen, D., \& Semmelroth, J. (1992). Sex differences in jealousy: Evolution, physiology, and psychology. Psychological Science, 3, 251-255.

Buss, D. M., \& Greiling, H. (1999). Adaptive individual differences. Journal of Personality, 67(2), 209-243. http://dx.doi.org/10.1111/1467-6494.00053.

Buss, D. M., \& Shackelford, T. K. (1997). Susceptibility to infidelity in the first year of marriage. Journal of Research in Personality, 31(2), 193-221.

Buss, D. M., \& Penke, L. (2014). Evolutionary personality psychology. In The APA handbook of personality and social psychology. In R. Larsen \& L. Cooper (Eds.). Personality processes and individual differences (Vol. 4). Washington, D.C.: APA Press.

Caruso, J. C. (2000). Reliability generalization of the NEO personality scales Educational and Psychological Measurement, 60(2), 236-254. http://dx.doi.org/ $10.1177 / 00131640021970484$.

Cohen, S., \& Williamson, G. M. (1991). Stress and infectious disease in humans Psychological Bulletin, 109, 5-24.

Costa, P. T., \& McCrae, R. R. (1985). The NEO personality inventory manual. Odessa, FL: Psychological Assessment Resources.

Dall, S. R. X., Houston, A., \& McNamara, J. (2004). The behavioural ecology of personality: Consistent individual differences from an adaptive perspective. Ecology Letters, 7(8), 734-739.

Daly, M., \& Wilson, M. (1983). Sex, evolution, and behavior. Boston: Willard Grant.

DeKay, W. T., \& Buss, D. M. (1992). Human nature, individual differences, and the importance of context: Perspectives from evolutionary psychology. Current Directions in Psychological Science, 1, 184-189.

Denissen, J. J. A., \& Penke, L. (2008). Self-esteem reactions to social interactions: Evidence for sociometer mechanisms across days, people, and nations. Journal of Personality and Social Psychology, 95(1), 181-196. http://dx.doi.org/10.1037/ 0022-3514.95.1.181.

Digman, J. M. (1997). Higher-order factors of the Big Five. Journal of Personality and Social Psychology, 73, 1246-1256.

Dion, K. K. (1972). Physical attractiveness and evaluation of children's transgressions. Journal of Personality and Social Psychology, 24(2), 207-213. http://dx.doi.org/10.1037/h0033372.

Doutrelant, C., \& McGregor, P. K. (2000). Eavesdropping and mate choice in female fighting fish. Behaviour, 137(12), 1655-1669.

Duckworth, A. (2010). Evolution of personality: Developmental constraints on behavioral flexibility. The Auk, 127(4), 752-758.

Dugatkin, L. A. (1992). Tendency to inspect predators predicts mortality risk in the guppy (Poecilia reticulata). Behavioral Ecology, 3(2), 124-127. http://dx.doi.org/ $10.1093 /$ beheco/3.2.124.

Ellis, L. (1987). Relationships of criminality and psychopathy with eight other apparent behavioral manifestations of sub-optimal arousal. Personality and Individual Differences, 8(6), 905-925. http://dx.doi.org/10.1016/01918869(87)90142-5.

Field, C. A., \& O'Keefe, G. (2004). Behavioral and psychological risk factors for traumatic injury. Journal of Emergency Medicine, 26(1), 27-35. http://dx.doi.org 10.1016/j.jemermed 2003.04.004.

Figueredo, A. J., Sefcek, J. A., Vasquez, G., Brumbach, B. H., King, J. E., \& Jacobs, W. J (2005). Evolutionary personality psychology. In D. M. Buss (Ed.), The handbook of evolutionary psychology (pp. 851-877). Hoboken, New Jersey: John Wiley \& Sons.

Fink, B., Neave, N., Manning, J. T., \& Grammer, K. (2005). Facial symmetry and the 'big-five' personality factors. Personality and Individual Differences, 39(3) 523-529. http://dx.doi.org/10.1016/j.paid.2005.02.002.

Flehmig, H. C., Steinborn, M., Langner, R., \& Westhoff, K. (2007). Neuroticism and the mental noise hypothesis: Relationships to lapses of attention and slips of action in everyday life. Psychological Science, 49(4), 343-360.

Funder, D. C. (2001). Personality. Annual Review of Psychology, 52, 197-221.

Funder, D. C., \& Colvin, C. R. (1991). Explorations in behavioral consistency: Properties of persons, situations, and behaviors. Journal of Personality and Socia Psychology, 60(5), 773-794. http://dx.doi.org/10.1037/0022-3514.60.5.773.

Gallagher, D. J. (1990). Extraversion, neuroticism, and appraisal of stressful academic events. Personality and Individual Differences, 11(10), 1053-1057.

Gangestad, S. W., Merriman, L. A., \& Thompson, M. E. (2010). Men's oxidative stress, fluctuating asymmetry, and physical attractiveness. Animal Behavior, 80, 1005-1013. http://dx.doi.org/10.1016/j.anbehav.2010.09.003.

Garamszegi, L. Z., Eens, M., \& Török, J. (2008). Birds reveal their personality when singing. PLoS ONE, 3(7), 2647. http://dx.doi.org/10.1371/journal.pone.0002647.

Glaser, R., \& Kiecolt-Glaser, J. K. (2005). Stress-induced immune dysfunction: Implications for health. Nature Reviews: Immunology, 5, 243-251.

Godin, J. G. J., \& Davis, S. A. (1995). Who dares, benefits: Predator approach behavior in the guppy (Poecilia reticulata) deters predator pursuit. Proceedings of the Royal Society of London B, 259(1355), 193-200. http://dx.doi.org/10.1098/ rspb.1995.0028. 
Godin, J. G. J., \& Dugatkin, L. A. (1996). Female mating preferences for bold males in the guppy, Poecilia reticulata. Proceedings of the National Academy of Sciences, 93(19), 10262-10267.

Gosling, S. D., \& John, O. P. (1999). Personality dimensions in nonhuman animals: A cross-species review. Current Directions in Psychological Science, 8(3), 69-79.

Grant, S. (2011). Neuroticism. United States: Nova Science Publishers Inc.

Haselton, M. G., \& Miller, G. F. (2006). Women's fertility across the cycle increases the short-term attractiveness of creative intelligence. Human Nature, 17(1) 50-73. http://dx.doi.org/10.1007/s12110-006-1020-0.

Hemenover, S. H. (2001). Self-reported processing bias and naturally occurring mood: Mediators between personality and stress appraisal. Personality and Social Psychology Bulletin, 27(4), 387-394.

Hemenover, S. H., \& Dienstbier, R. A. (1996). Prediction of stress appraisals from mastery, extraversion, neuroticism, and general appraisal tendencies. Motivation and Emotion, 20, 299-318.

Herbert, T. B., \& Cohen, S. (1993). Stress and immunity in humans: A meta-analytic review. Psychosomatic Medicine, 55(4), 364-379.

Holtzman, N. S., Augustine, A. A., \& Senne, A. L. (2011). Are pro-social or socially aversive people more physically symmetrical? Symmetry in relation to over 200 personality variables. Journal of Research in Personality, 45(6), 687-691. http:// dx.doi.org/10.1016/j.jrp.2011.08.003.

Jokela, M., Kivimaki, M., Elovainio, M., \& Keltikangas-Jarvinen, L. (2009). Personality and having children: A two-way relationship. Journal of Personality and Social Psychology, 96, 218-230.

Judge, T. A., Livingston, B. A., \& Hurst, C. (2011). Do nice guys - and gals really finish last? The joint effects of sex and agreeableness on income. Journal of Personality and Social Psychology, 102(2). http://dx.doi.org/10.1037/ a0026021.

Kanazawa, S. (2011). Evolutionary psychology and individual differences. In T. Chamorro-Premuzic, S. von Stumm, \& A. Furnham (Eds.), The handbook of individual differences (pp. 353-376). Oxford: Blackwell-Wiley.

Kretschmer, E. (1931). The breeding of the mental endowments of genius. Eugenics, $4,6-11$.

Kuppens, P., \& Van Mechelen, I. (2007). Interactional appraisal models for the anger appraisals of threatened self-esteem, other-blame, and frustration. Cognition $\mathcal{E}$ Emotion, 21, 56-77. http://dx.doi.org/10.1080/02699930600562193.

Kurzban, R., \& Leary, M. (2001). Evolutionary origins of stigmatization: The functions of social exclusion. Psychological Bulletin, 127(2), 187-208.

Lewis, D. M. G. (2011). The sibling uncertainty hypothesis: Facial resemblance as a sibling recognition cue. Personality and Individual Differences, 51, 969-974.

Lewis, D. M. G. (2013). Individual differences and universal condition-dependent mechanisms (Unpublished doctoral dissertation). Austin: The University of Texas.

Lewis, D. M. G., Al-Shawaf, L., Yilmaz, C. (2014). The openness-calibration hypothesis: Openness to experience and novel mating opportunities, submitted for publication.

Li, N. P., Bailey, J. M., Kenrick, D. T., \& Linsenmeier, J. A. W. (2002). The necessities and luxuries of mate preferences: Testing the tradeoffs. Journal of Personality and Social Psychology, 82, 947-955.

Li, N., \& Kenrick, D. (2006). Sex similarities and differences in preferences for shortterm mates: What, whether and why. Journal of Personality and Socia Psychology, 90(3), 468-489.

Lieberman, D. Tooby, J., \& Cosmides, L. (2003). Does morality have a biologica basis? An empirical test of the factors governing moral sentiments relating to incest. Proceedings of the Royal Society London (Biological Sciences), 270(1517), $819-826$.

Lieberman, D., Tooby, J., \& Cosmides, L. (2007). The architecture of human kin detection. Nature, 445, 727-731. http://dx.doi.org/10.1038/nature05510.

Lund, O. C. H., Tamnes, C. K., Mouestue, C., Buss, D. M., \& Vollrath, M. (2007). Tactics of hierarchy negotiation. Journal of Research in Personality, 41, 25-44.

Lukaszewski, A. W. (2013). Testing an adaptationist theory of trait covariation Relative bargaining power as a common calibrator of an interpersonal syndrome. European Journal of Personality. http://dx.doi.org/10.1002/ per.1908.

Lukaszewski, A. W., Larson, C. M., Gildersleeve, K. A., Roney, J. R., \& Haselton, M. G. (2014). Condition-dependent calibration of men's uncommitted mating orientation: Evidence from multiple samples. Evolution and Human Behavior, 35(4), 319-326. http://dx.doi.org/10.1016/j.evolhumbehav.2014.03.002.

Lukaszewski, A. W., \& Roney, J. R. (2011). The origins of extraversion: Joint effects of facultative calibration and genetic polymorphism. Personality and Socia Psychology Bulletin, 37(3), 409-421.

MacDonald, K. (2006). Evolution, the five factor model, and levels of personality. Journal of Personality, 63(3), 525-567.

Mathes, E. W., \& Kahn, A. (1975). Physical attractiveness, happiness, neuroticism, and self-esteem. Journal of Psychology, 90, 27-30.

McCrae, R. R., \& Costa, P. T. (2008). The five factor theory of personality. In O. P. John, R. W. Robins, \& L. A. Pervin (Eds.), Handbook of personality psychology: Theory and research (3rd ed., pp. 159-181). New York: Guilford Press.

McCreery, C., \& Claridge, G. (2002). Healthy schizotypy: The case of out-of-the-body experiences. Personality and Individual Differences, 32(1), 141-154. http:/ dx.doi.org/10.1016/S0191-8869(01)00013-7.

McDonald, M., Navarrete, C., \& Van Vugt, M. (2011). Evolution and the psychology of intergroup conflict: The male warrior hypothesis. Philosophical Transactions of The Royal Society of London, 367(1589), 670-679.

Neeleman, J., Sytema, S., \& Wadsworth, M. (2002). Propensity to psychiatric and somatic ill-health: Evidence from a birth cohort. Psychological Medicine, 32 793-803. http://dx.doi.org/10.1017/S0033291702005901.
Nettle, D. (2005). Happiness: The science behind your smile. Oxford: Oxford University Press.

Nettle, D. (2006). The evolution of personality variation in humans and other animals. American Psychologist, 61(6), 622-631. http://dx.doi.org/10.1037/0003066X.61.6.622.

Nettle, D. (2009). An evolutionary model of low mood states. Journal of Theoretical Biology, 257, 100-103.

O'Leary, A. (1990). Stress, emotion, and human immune function. Psychological Bulletin, 108(3), 363-382.

Ophir, A. G., \& Galef, B. G. (2003). Female Japanese quail that 'eavesdrop' on fighting males prefer loser over winners. Animal Behaviour, 66(2), 399-407. http:/ dx.doi.org/10.1006/anbe.2003.2230.

Ophir, A. G., Persaud, K. N., \& Galef, B. G. (2005). Avoidance of relatively aggressive male Japanese quail (Coturnix japonica) by sexually experienced conspecific females. Journal of Comparative Psychology, 119(1), 3-7. http://dx.doi.org/ 10.1037/0735-7036.119.1.3.

Ozer, D. J. (1985). Correlation and the coefficient of determination. Psychological Bulletin, 97(2), 307-315. http://dx.doi.org/10.1037/0033-2909.97.2.307.

Penke, L., Denissen, J. J. A., \& Miller, G. F. (2007). The evolutionary genetics of personality. European Journal of Personality, 21(5), 549-587. http://dx.doi.org/ 10.1002/per.629.

Pound, N., Penton-Voak, I. S., \& Brown, W. M. (2007). Facial symmetry is positively associated with self-reported extraversion. Personality and Individual Differences, 43(6), 1572-1582. http://dx.doi.org/10.1016/j.paid. 2007.04.014.

Roberts, B. W., Kuncel, N. R., Shiner, R., Caspi, A., \& Goldberg, L. R. (2007). The power of personality: The comparative validity of personality traits, socioeconomic status, and cognitive ability for predicting important life outcomes. Perspectives on Psychological Science, 2(4), 313-345. http://dx.doi.org/10.1111/j.17456916.2007.00047.x.

Ross, L., \& Nisbett, R. E. (1991). The person and the situation: Perspectives of social psychology. New York, NY: McGraw-Hill.

Rushton, J. P., \& Irwing, P. (2008). A general factor of personality (GFP) from two meta-analyses of the Big Five: Digman (1997) and Mount, Barrick, Scullen, and Rounds (2005). Personality and Individual Differences, 45, 679-683.

Schmitt, D. P. (2004). The Big Five related to risky sexual behaviour across 10 world regions: Differential personality associations of sexual promiscuity and relationship infidelity. European Journal of Personality, 18, 301-319.

Schuett, W., \& Dall, S. R. X. (2009). Sex differences, social context and personality in zebra finches, Taeniopygia guttata. Animal Behaviour, 77(5), 1041-1050. http:// dx.doi.org/10.1016/j.anbehav.2008.12.024.

Sen, S., Burmeister, M., \& Ghosh, D. (2004). Meta-analysis of the association between a serotonin transporter promoter polymorphism (5-HTTLPR) and anxiety-related personality disorders. American Journal of Genetics Part B: Neuropsychiatric Genetics, 127B(1), 85-89.

Shackelford, T. K., \& Larsen, R. J. (1997). Facial asymmetry as an indicator of psychological, emotional, and physiological distress. Journal of Personality and Social Psychology, 72(2), 456-466. http://dx.doi.org/10.1037/00223514.72.2.456

Sheldon, W. H. (1940). The varieties of human physique. New York: Harper.

Sheldon, W. H. (1942). The varieties of temperament. New York: Harper.

Sih, A., Bell, A. M., Johnson, J. C., \& Ziemba, R. E. (2004). Behavioral syndromes: An integrative overview. The Quarterly Review of Biology, 79, 241-277.

Simmons, Z. L., \& Roney, J. R. (2011). Variation in CAG repeat length of the androgen receptor gene predicts variables associated with intrasexual competitiveness in human males. Hormones and Behavior, 60, 306-312. http://dx.doi.org/10.1016/ j.yhbeh.2011.06.006.

Smith, B. R., \& Blumstein, D. T. (2008). Fitness consequences of personality: A metaanalysis. Behavioral Ecology, 19(2), 448-455. http://dx.doi.org/10.1093/beheco/ $\operatorname{arm} 144$.

Srivastava, S., John, O. P. Gosling S. D. \& Potter, J. (2003). Development of personality in early and middle adulthood: Set like plaster or persistent change? Journal of Personality and Social Psychology, 84(5), 1041-1053.

Stephan, C. W., \& Langlois, J. H. (1984). Baby beautiful: Adult attributions of infant competence as a function of infant attractiveness. Child Development, 55(2), 576-585.

Tochigi, M., Otowa, T., Suga, M., Rogers, M., Minato, T., Yamasue, H., et al. (2006). Association between dopamine D4 receptor (DRD4) exon III polymorphism and neuroticism in the Japanese population. Neuroscience Letters, 398(3), 333-336. http://dx.doi.org/10.1016/j.neulet.2006.01.020.

Tomkins, J. L., Radwan, J., Kotiaho, J. S., \& Tregenza, T. (2004). Genic capture and resolving the lek paradox. Trends in Ecology and Evolution, 19, 323-328. http:// dx.doi.org/10.1016/j.tree.2004.03.029.

Tooby, J., \& Cosmides, L. (1990). On the universality of human nature and the uniqueness of the individual: The role of genetics and adaptation. Journal of Personality, 58(1), 17-67. http://dx.doi.org/10.1111/j.1467-6494.1990. tb00907.x.

Tufto, J. (2000). The evolution of plasticity and nonplastic spatial and temporal adaptations in the presence of imperfect environmental cues. American Naturalist, 156, 121-123.

Vannatta, K., Gartstein, M. A., Zeller, M., \& Noll, R. B. (2009). Peer acceptance and social behavior during childhood and adolescence: How important are appearance, athleticism, and academic competence? International Journal of Behavioral Development, 33(4), 303-311. http://dx.doi.org/10.1177/01650254 08101275 
Vaughn, B. E., \& Langlois, J. H. (1983). Physical attractiveness as a correlate of peer status and social competence in preschool children. Developmental Psychology, 19(4), 561-567. http://dx.doi.org/10.1037/0012-1649.19.4.561.

Verweij, K. J. H., Yang, J., Lahti, J., Veijola, J., Hintsanen, M., Pulkki-Raback, L., et al. (2012). Maintenance of genetic variation in human personality: Testing evolutionary models by estimating heritability due to common causal variants and investigating the effect of distant inbreeding. Evolution, 66(10), 3238-3251.

Waynforth, D. (2001). Mate choice trade-offs and women's preference for physically attractive men. Human Nature, 12(3), 207-219. http://dx.doi.org/10.1007/ s12110-001-1007-9.
Westberg, L., Henningsson, S., Landén, M., Annerbrink, K., Melke, J., Nilsson, S., et al (2009). Influence of androgen receptor repeat polymorphisms on personality traits in men. Journal of Psychiatry and Neuroscience, 34(3), 205-211.

Wolf, M., van Doorn, G. S., Leimar, O., \& Weissing, F. J. (2007). Life-history trade-offs favour the evolution of animal personalities. Nature, 447, 581-584. http:// dx.doi.org/10.1038/nature05835.

Zietsch, B. P., Verweij, K. J. H., Bailey, J. M., Wright, M. J., \& Martin, N. G. (2010) Genetic and environmental influences on risky sexual behavior and its relationship with personality. Behavior Genetics, 40, 12-21. 